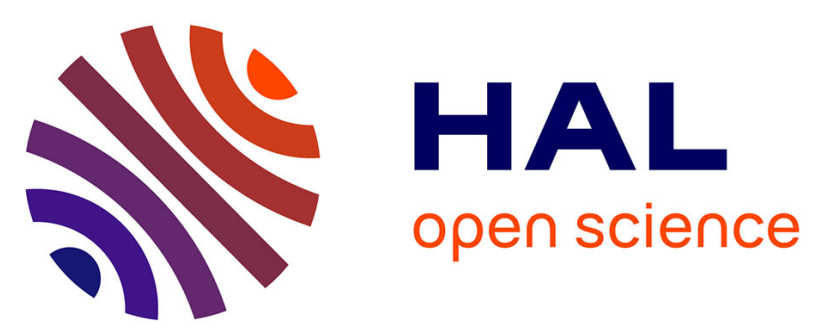

\title{
Impact of the Nocturnal Low-Level Jet and Orographic Waves on Turbulent Motions and Energy Fluxes in the Lower Atmospheric Boundary Layer
}

Sayahnya Roy, Alexei Sentchev, François G Schmitt, Patrick Augustin, Marc Fourmentin

\section{To cite this version:}

Sayahnya Roy, Alexei Sentchev, François G Schmitt, Patrick Augustin, Marc Fourmentin. Impact of the Nocturnal Low-Level Jet and Orographic Waves on Turbulent Motions and Energy Fluxes in the Lower Atmospheric Boundary Layer. Boundary-Layer Meteorology, 2021, 180 (3), pp.527-542. 10.1007/s10546-021-00629-x . hal-03319673

\section{HAL Id: hal-03319673 https://hal.science/hal-03319673}

Submitted on 12 Aug 2021

HAL is a multi-disciplinary open access archive for the deposit and dissemination of scientific research documents, whether they are published or not. The documents may come from teaching and research institutions in France or abroad, or from public or private research centers.
L'archive ouverte pluridisciplinaire HAL, est destinée au dépôt et à la diffusion de documents scientifiques de niveau recherche, publiés ou non, émanant des établissements d'enseignement et de recherche français ou étrangers, des laboratoires publics ou privés. 


\title{
1 Impact of the Nocturnal Low-Level Jet and Orographic Waves \\ 2 on Turbulent Motions and Energy Fluxes in the Lower \\ 3 Atmospheric Boundary Layer
}

\author{
4 Sayahnya Roy ${ }^{1,2}$ - Alexei Sentchev ${ }^{1}$ - François G. Schmitt ${ }^{1}$ - Patrick Augustin ${ }^{2}$ • Marc \\ 5 Fourmentin ${ }^{2}$
}

6 Received: DD Month YEAR/ Accepted: DD Month YEAR/ Published online: DD Month YEAR

7 C) Springer Science + Business Media B. V.

8 Abstract The nocturnal low-level jet (LLJ) and orographic (gravity) waves play an

9 important role in the generation of turbulence and pollutant dispersion and can affect the 10 energy production by wind turbines. Additionally, gravity waves have an influence on the

11 local mixing and turbulence within the surface layer and the vertical flux of mass into the 12 lower atmosphere. On 25 September 2017 during a field campaign, a persistent easterly LLJ 13 and gravity waves are observed simultaneously in a coastal area in the north of France. In 14 the present study, an attempt is to explore the variability of the wind speed, turbulent eddies, 15 and turbulence kinetic energy in the time-frequency and space domain using an ultrasonic 16 anemometer and a scanning wind lidar. The results reveal a significant enhancement of the 17 turbulence kinetic energy dissipation (by $\sim 50 \%$ ) due to gravity waves in the LLJ shear layer 18 (below the jet core) during the period of wave propagation. Large values of zonal and vertical 19 components of the shear stress $\left(\sim|0.4|\right.$ and $\sim 1.5 \mid \mathrm{m}^{2} \mathrm{~s}^{-2}$ respectively) are found during that 20 period. Large size eddies ( $\sim 10$ to $280 \mathrm{~m}$ ), matching high-speed wind regime, are found to 21 propagate the momentum downward. This enhances the downward mass transport from the 22 LLJ shear layer to the roughness layer. Furthermore, these large-scale eddies are associated 23 with the crests while comparatively small-scale eddies are associated with the troughs of the 24 gravity wave.

凶 Sayahnya Roy

email. sayahnya1110@gmail.com

1 Univ. Littoral Cote d'Opale, Univ. Lille, CNRS, UMR 8187, LOG, Laboratoire d'Océanologie et de Géosciences, F 62930 Wimereux, France.

2 Univ. Littoral Côte d'Opale, EA 4493, LPCA, Laboratoire de Physico-Chimie de l'Atmosphère, 59140, Dunkerque, France. 
25 Keywords Lidar measurements - Low-level Jet • Probability Density Function - Sonic

26 Anemometer $\bullet$ Turbulent eddies

\section{Introduction}

29 After sunset, strong wind acceleration at the altitude 100-200 m above ground level (a.g.1.)

30 is frequently observed. This phenomenon, known as the nocturnal low-level jet (LLJ), is

31 defined as concentrated airflow within the atmospheric boundary layer (ABL) over sea or

32 land surface (Banta et al. 2003). The maximum jet velocity is influenced by several factors

33 such as horizontal temperature gradients, orographic features, elevated turbulence level,

34 etc. (Birgitta 1998; Kallistratova et al. 2013). Moreover, LLJs can be formed by synoptic

35 cold fronts, thunderstorm gustfronts, drainage-flow fronts, and sea-breeze fronts. Bowen

36 (1996), Droegemeier and Wilhelmson (1987), and Darby et al. (2002) characterized the

37 LLJ profile after the front within a cold-air layer. Also, Whiteman et al. (1997) provided a

38 description of an LLJ generated at a cold-air front by large-scale density currents.

39 Furthermore, nocturnal LLJs are found to be generated by atmospheric pressure gradients

40 and baroclinitity (Hoecker 1963; Bonner 1968; Mitchell et al. 1995; Zhong et al. 1996),

41 which has been widely studied to detect its influence in severe weather conditions

42 (Stensrud 1996). Prabha et al. (2008) showed that a high wind speed may occur not only

43 in the vicinity of the ABL top, but also in the shear layer, i.e. from 10 to $100 \mathrm{~m}$ a.g.l. Kaimal

44 and Finnigan (1994) noted that the maximum turbulence exchange occurs between a

45 canopy and the atmosphere, due to the coherent wind structures of the size of the canopy.

46 Further, Raupach et al. (1996) documented large-scale eddies generated by the interaction

47 of the wind with a large canopy (large surface roughness). They observed a modulation of

48 the eddies's size by turbulence, and showed that flow instabilities are governed by the wind

49 velocity shears.

50 Wind velocity fluctuations near the surface are involved in a cyclic process. In this

51 process the wind propagating slowly in the surface layer can be accelerated rapidly within

52 the outer layer (the uppermost $90 \%$ of the ABL, according to Rotach and Calanca 2015).

53 This is known as a "turbulent bursting event". The downbursts due to the large roughness

54 heights were observed by Hunt and Durbin (1999) within the lower layer. Furthermore, 
55 Smedman et al. (2004) showed that this type of phenomenon could be observed in the 56 presence of a LLJ tied to intense shear.

57 In the present study, an undulating motion generated by gravity or orographic waves 58 collocated with a LLJ has been observed in the lower ABL. Hoffmann et al. (2013) reported 59 that the source of many gravity waves is related to orographic features. It was also 60 documented in several studies (e.g., Fritts and Nastrom 1992; Eckermann and Vincent 61 1993; Plougonven and Teitelbaum 2003) that low-frequency gravity waves occurred in the 62 area surrounding jets and fronts, particularly in the upper troposphere regions. Those large63 scale gravity waves are known as inertia-gravity waves (Uccellini and Koch 1987; Guest 64 et al. 2000).

65 Gravity-wave motions are observed in the free atmosphere when the Brunt-Väisälä 66 period of oscillations in positively stratified air changes to the inertial period. Mountain67 waves are one of the specific cases. In the lower troposphere, wind blowing over small hills 68 starts oscillating vertically. The Coriolis force creates individual elliptic shape in the plane 69 of wind propagation and perhaps gives rise to low frequency, horizontal, inertia gravity 70 waves. These waves are frequently observed at mid-latitudes, especially in the lower 71 atmosphere (Vaughan and Hooper 2015). Recently, Wei et al. (2017) demonstrated that 72 events with small wind speed, large-scale motions (e.g., gravity waves, mesoscale 73 disturbances, or synoptic-scale variability) were capable of generating small- to large-scale 74 turbulent eddies.

75 Recent studies have focused on assessing ABL phenomena, such as LLJ or gravity 76 waves, individually (Teixeira 2014; Soufflet et al. 2019). Also, some studies focused on 77 the low-level gravity waves (Tepper 1950; Abdullah 1955). They revealed that low-level 78 gravity waves produce vertical motions, which are capable of forming convective storms.

79 Recently, Du and Chen (2019) studied the mesoscale impacts of wavelike disturbances of 80 double LLJs on convection initiation mechanisms. This recent research highlighted the 81 need to improve understanding of the relationship between gravity waves and high 82 frequency turbulence in the lower ABL. The gap of knowledge is related to the insufficient 83 simultaneous observations of both phenomena.

84 In the present study, we focus on assessing the turbulence characteristics (such as 85 turbulence kinetic energy and momentum fluxes) in the lower ABL, at $10 \mathrm{~m}$ height above 
86 the ground, and their modulation by gravity waves propagating at large distance from the

87 ground. We also quantify the distribution of turbulent eddies in time-space and frequency

88 domain and identify the direction of kinetic energy transfer generated by turbulent eddies

89 toward the roughness layer (extending up to a few metres from the ground level).

90 Moreover, we assess the variability of turbulence kinetic energy (TKE) dissipation,

91 turbulence length scales, momentum fluxes, and turbulent bursting events in the presence

92 of a gravity wave collocated with a LLJ. The paper is organized as follows. In Sect. 2, we

93 present the data and the methods of analysis. Section 3 contains the discussion of our

94 results. Section 4 concludes the study and gives some implications of the observed large-

95 scale motions in the ABL on turbulence near the ground.

\section{Data and Methods}

\section{$98 \quad 2.1$ Study Site and Wind Measurements}

99 In the frame of the EMPATIE project (Multiscale study of turbulent atmospheric 100 phenomena and their influences on wind power), an atmospheric mobile unit (UMA) was 101 deployed on 25 September 2017 (Fig. 1), near the seashore at Boulogne-sur-Mer (France).

102 Wind profiles were measured using a scanning Doppler wind lidar (LEOSPHERE, 103 Windcube WLS 100) and a sonic anemometer (model USA-1, Metek GmbH). The pulsed 104 Doppler lidar operates at $1543 \mathrm{~nm}$ and uses a heterodyne technique to measure the Doppler 105 shift of laser radiation backscattered by the aerosols (Augustin et al. 2020). The wind speed 106 is estimated from the Doppler shift at different vertical levels. More technical details are 107 given by Ruchith et al. (2015) and Kumer et al. (2016). During the experiment, the lidar 108 performed, consecutively, range-height indicator (RHI) scans along the north-south and 109 east-west and Doppler beam swinging (DBS) techniques (Kumer et al. 2016). The DBS

110 technique has been used to determine the temporal evolution of horizontal wind velocity 111 profiles. The RHI scans allowed us to observe the vertical and spatial structure of the lower 112 troposphere from the ground to few kilometres with a blind zone of $100 \mathrm{~m}$ around the lidar. 113 Moreoever, vertical profiles from RHI scans have been used to measure directly the vertical 114 wind speed. The measurement strategy was constituted of two $180^{\circ} \mathrm{RHI}$ scans along east115 west and south-north axes with $1^{\circ}$ resolution ( 3 min duration per each RHI scan), and a $11675^{\circ}$ elevation DBS technique (1 min duration). 
Two particular periods of lidar observations were considered: the first period, P-I, from

1181800 to 0000 UTC (from sunset to midnight) and the second period, P-II, from 0000 to

1190600 UTC (from midnight to sunrise). During P-I, a LLJ collocated with gravity waves

120 was observed in the lower troposphere. However, both phenomena (the LLJ and gravity 121 waves) dissipated during P-II.

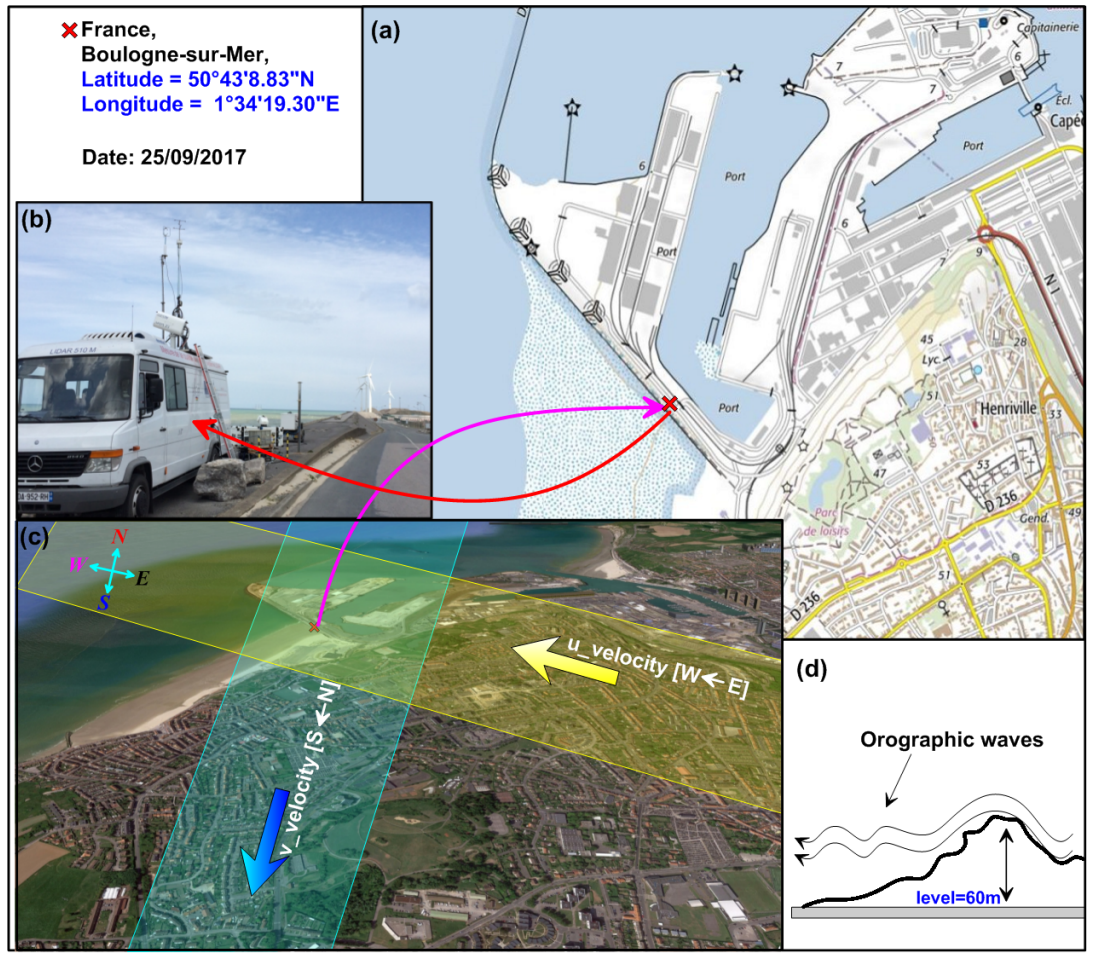

123 Fig. 1 Location and period of measurements in Boulogne-sur-Mer. (a) Map of topographical levels, (b) 124 mobile atmospheric data acquisition unit of the University of Littoral Côte d'Opale located on the seashore 125 (red cross) equipped with a sonic anemometer and lidar (Windcube WLS 100), (c) satellite image of the study 126 area with the indication of wind directions, (d) schematic of orographic waves due to easterly wind over 127 elevated topography

129 Lidar measurements were complemented by the data from an ultrasonic anemometer 130 operating at $10-\mathrm{Hz}$ (from 1800 to 0600 UTC) and provided three components of the wind 131 velocity and temperature variations. This sonic anemometer was deployed in the roughness 132 layer on a $7 \mathrm{~m}$ mast in the blind zone of the lidar. Indeed, the lidar near-field is affected by 133 an incomplete overlap between the laser beam and the field-of-view of a telescope 134 corresponding to the blind zone of the lidar. No data could be recorded in this zone. The 135 first gate was $100 \mathrm{~m}$ and the along-beam spatial resolution was $50 \mathrm{~m}$. 


\section{$136 \quad 2.2$ Methodology}

137 The velocity components $u, v$, and $w$ of the wind flow (measured by ultrasonic

138 anemometer) are decomposed into a mean part and fluctuating part as

$$
u=\bar{u}+u^{\prime}, v=\bar{v}+v^{\prime}, w=\bar{w}+w^{\prime},
$$

139 where $u, v, w$ are three components of the instantaneous velocity vector, $\bar{u}, \bar{v}, \bar{w}$ are 10 -min 140 averaged components and $u^{\prime}, v^{\prime}$, and $w^{\prime}$ are the corresponding velocity fluctuations. Note

141 that the positive zonal component $u$ represents the wind blowing from the west, the positive

142 meridional component $v$ characterizes the wind blowing from the south, and the positive

143 vertical component $w$ describes the wind blowing upward.

144 The time-averaged Reynolds shear stress components are defined as

$$
R_{u v}=-\overline{u^{\prime} v^{\prime}} ; R_{u w}=-\overline{u^{\prime} w^{\prime}} ; R_{v w}=-\overline{v^{\prime} w^{\prime}},
$$

145 and the turbulence kinetic energy (TKE) can be written as

$$
T K E=\frac{1}{2}\left(\overline{u^{\prime 2}}+\overline{v^{\prime 2}}+\overline{w^{\prime 2}}\right) .
$$

146 To understand the distribution of the turbulent eddy structures in the frequency domain and

147 the maximum energy-carrying frequency of the wind velocity signal, spectral analysis was 148 performed using the FFT (fast Fourier transform) algorithm. The turbulence dissipation

149 rate $(\varepsilon)$ is estimated from instantaneous wind measurements by sonic anemometer using

150 two different methods: the energy spectra method and the second-order structure function

151 method. The velocity spectrum, which satisfies the $-5 / 3$ slope within the inertial subrange

152 (Kolmogorov 1941), can be defined as

$$
E(k)=\alpha \varepsilon^{2 / 3} k^{-5 / 3},
$$

153 where $k$ is the wavenumber and $\alpha$ is the Kolmogorov constant $(\alpha=0.52)$. The conversion

154 of the spectrum from wavenumber to frequency domain is based on Taylor's frozen

155 turbulence hypothesis (Taylor 1935) providing

$$
k=2 \pi f / \bar{U},
$$

156 where $\bar{U}$ is the mean wind speed. The turbulence dissipation rate is computed using one157 dimensional velocity spectrum $S_{u}(f)$ in the inertial subrange (Champagne et al. 1977) as

$$
\varepsilon=\frac{2 \pi}{\bar{U}}\left(\frac{f^{5 / 3} s_{u}(f)}{\alpha}\right)^{3 / 2} .
$$


158 Further, velocity increments within the inertial subrange can be conveyed as the second159 order structure function (SF2) using Kolmogorov's hypothesis, and it can be 160 interconnected to $\varepsilon$ as

$$
S F 2_{u}(r)=\overline{[u(x+r)-u(x)]^{2}}=\frac{1}{\alpha} \varepsilon^{2 / 3} r^{2 / 3},
$$

161 where $r$ represents the spatial separations within the inertial subrange, which can be also 162 expressed as temporal velocity increments by applying Taylor's frozen turbulence 163 hypothesis. Finally, $\varepsilon$ can be calculated (similar to Bodini et al. 2018) from the second164 order structure function as

$$
\varepsilon=\frac{1}{\bar{U} \tau}\left[\alpha S F 2_{u}(\tau)\right]^{3 / 2},
$$

165 where $S F 2_{u}(\tau)$ is the second-order structure function for velocity $u$ with respect to 166 temporal increments $\tau$. The turbulent length scale $(L)$ is computed as

$$
L=\frac{T K E^{3 / 2}}{\varepsilon} \text {. }
$$

167 All these quantities are used in the subsequent analysis for assessing the wind 168 variability in the roughness layer modulated by gravity-wave interaction with the LLJ.

169 Reynolds shear stress depicts the direction of the momentum flux affected by a LLJ

170 collocated with gravity waves. Further, the variability of TKE and $\varepsilon$ shows the modulation 171 of the overall energy by large-scale motions in the ABL (LLJ and the gravity waves). Time 172 variability in wind energy is related to eddy motions of length scale given by $L$. Turbulent 173 energy propagates three-dimensionally and the dominant direction of an energy flux can 174 be quantified by the skewness. Turbulence bursts establish variations in the momentum 175 exchanges, demonstrated by the probability density distributions and joint distributions of 176 velocity fluctuations. In this study, quadrant analysis is used to demonstrate the impact of 177 gravity waves on the direction of high- and low-speed eddy propagation within the 178 roughness layer.

\section{Discussions of the Results}

\section{$181 \quad 3.1$ Temporal Variations of Wind}

182 The horizontal wind direction, and horizontal and vertical wind speed in the lower 183 atmosphere observed by Doppler lidar are shown in Fig. 2a, b. In general, northerly wind 184 is observed above the altitude $600 \mathrm{~m}$ from 2000 to 0600 UTC (wind speed $1 \mathrm{~m} \mathrm{~s}^{-1}$ to $4 \mathrm{~m}$ 
$\left.185 \mathrm{~s}^{-1}\right)$. However, below this altitude and above the ground, the wind direction changes to easterly for the whole period of observation. Large range of horizontal $\left(3.5\right.$ to $\left.8 \mathrm{~m} \mathrm{~s}^{-1}\right)$ and vertical $\left(-0.6\right.$ to $\left.0.3 \mathrm{~m} \mathrm{~s}^{-1}\right)$ wind speed variation are observed below $500 \mathrm{~m}$ during P-I.

188 During P-II (after 0000 UTC), the wind speed decreases in the whole layer covered by 189 observations.

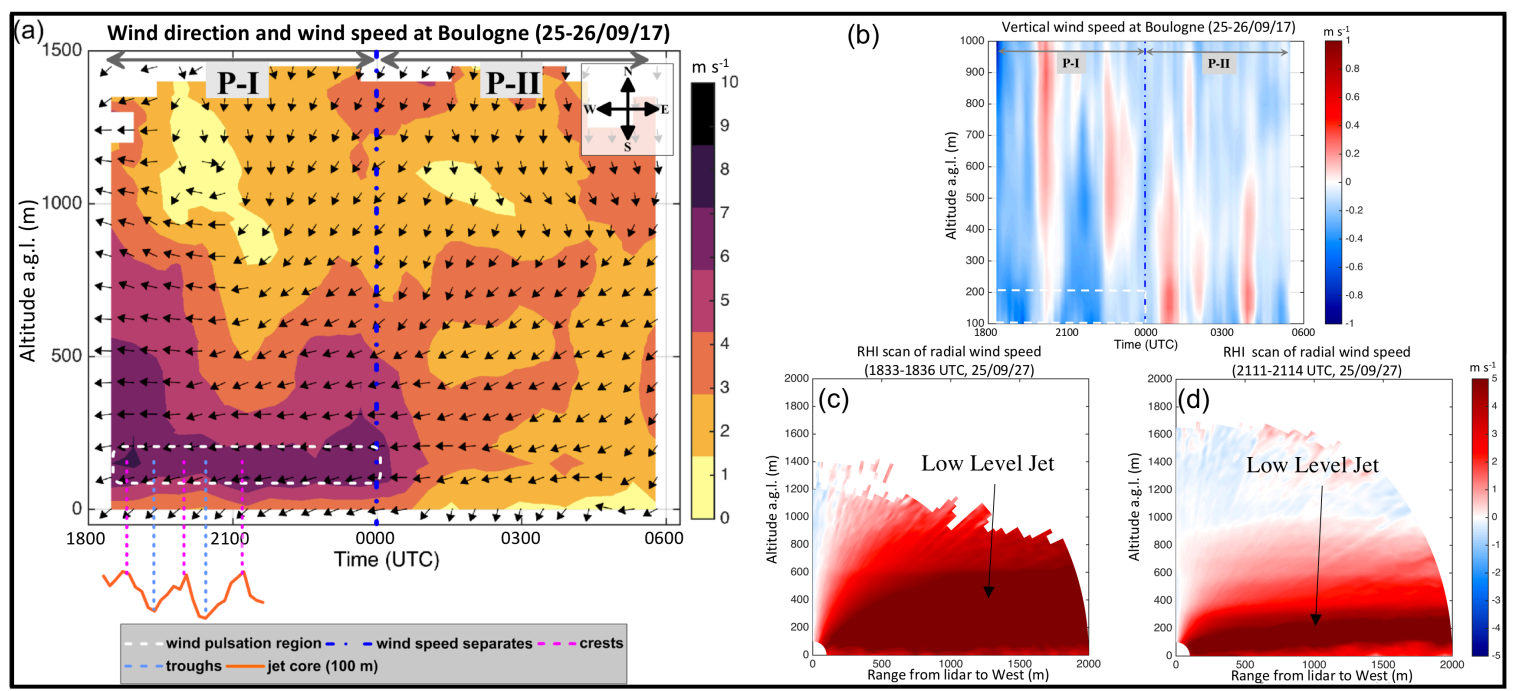

Fig. 2 Time-height cross-section of (a) horizontal wind direction (arrows) and speed (colour scale) and (b) vertical wind speed observed in Boulogne-sur-Mer on 25/09/17. Downward and leftward arrows represent northerly wind and easterly wind, respectively. The orange line (bottom of the figure) shows undulating patterns of maximum wind speed at $100 \mathrm{~m}$. The white dashed time window corresponds to the main location of the jet core observed. RHI scan of radial wind speed toward the sea at (c) 1833 UTC and (d) 2111 UTC illustrating the LLJ phenomenon (positive values indicate flow away from lidar).

198 In Fig. 2a, a blue dash-dot line separates this high-speed and low-speed wind periods in the 199 lower troposphere $(<500 \mathrm{~m})$. During P-I and in the lower troposphere, LLJ is clearly detected by the lidar (Figs. 2c, d). The RHI scan of radial wind speed toward the sea, 201 performed one hour after the sunset, shows a $500 \mathrm{~m}$ thick LLJ (Fig. 2c), which becomes 202 thinner and decouples from the ground at about 1930 UTC (Fig. 2d). However, during the 203 day and before the LLJ occurrence, surface wind speed was relatively low (between 2 and $2044 \mathrm{~m} \mathrm{~s}^{-1}$ ) and the wind direction was mainly easterly (not shown). Although during the night, 205 the wind speed was relatively hight $\left(>6 \mathrm{~m} \mathrm{~s}^{-1}\right)$, it decreased considerably from $6 \mathrm{~m} \mathrm{~s}^{-1}$ down 206 to $2 \mathrm{~m} \mathrm{~s}^{-1}$ after the sunrise at about 530 UTC (25/09/2017). The frictional force caused by 207 the turbulence associated with the heated ground during the day can decrease the wind 
208 speed. Conversely, at the sunset (about 1730 UTC), the daytime frictional force shut down 209 (due to the collapse of convective turbulence) and consequently the air mass accelerates 210 generating the LLJ. Figure $2 \mathrm{~d}$ represents a typical radial wind speed RHI scan obtained 211 after 1930 UTC and illustrates the shear located above and below the height of the LLJ 212 maximum wind speed (jet core), which can be an important source of turbulence, 213 particularly during the night. Observations at altitude levels ranging from 100 to $200 \mathrm{~m}$ 214 (white dashed rectangle in Fig. 2a, b) show the horizontal and vertical wind speed 215 variations. To investigate the nature of this variability in wind speed, we analyzed the 216 maximum wind speed at a fixed altitude of $100 \mathrm{~m}$ (jet core) as a function of time (Fig. 2a 217 bottom plot). Figure 2a (bottom plot) shows a sinusoidal oscillation of the wind speed. The 218 vertical wind velocity component $(w)$ within the jet core area shows fluctuation of 219 downward motion (Fig. 2b). A quasi-harmonic oscillation of $w$ is observed in the region 220 characterized by higher wind speed (P-I region in Fig. 2b). Later in time, during P-II, $w$ is 221 found to be chaotic (fluctuation of upward and downward motion). Therefore the 222 variability of the horizontal wind speed components modulates the vertical wind 223 component variability.

224 To further explore the mechanisms behind the wavy nature of the atmospheric flow 225 characterized by large speed $\left(U_{(\max )}\right)$, the temporal evolution of the temperature $(\xi)$, 226 pressure $(P)$, and $U_{(\max )}$ are compared in Fig. 3. Figure 3a shows an exponential decay of 227 temperature with time. The pressure $(P)$ increases until 2136, then decreases. Wavy 228 evolution of the wind speed is clearly seen in Fig. 3c. 


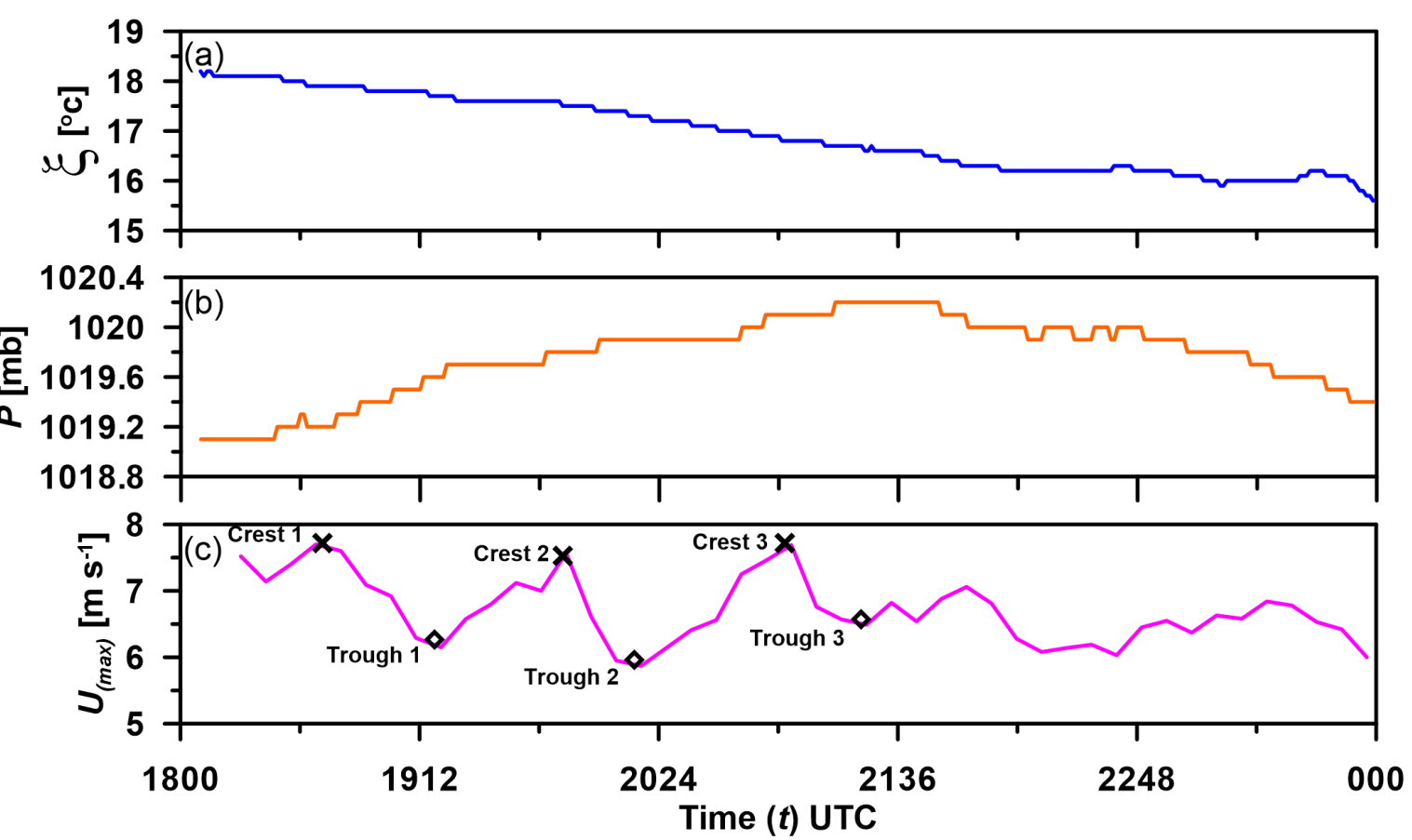
Time $(t)$ UTC

231 Fig. 3 Temporal variations of (a) temperature [ $\xi]$; (b) Pressure $[P]$ and (c) wind speed $\left[U_{(\max }\right]$ at $100 \mathrm{~m}$

233 The study site is characterized by a complex topography with elevated topographic 234 features $(50-100 \mathrm{~m})$ perpendicular to the wind. This causes gravity-wave generation and 235 velocity undulation. Other examples given in the literature (e.g., Lott and Teitelbaum 1993; 236 Tsuda 2014; Teixeira 2014; Sandu et al. 2019) and the present observations support the 237 hypothesis that the wavy nature of the wind speed is due to an orographic wave of $\sim 60$ 238 minutes propagating from east to west. Lott and Teitelbaum (1993) stated that wave 239 packets might be generated within the roughness layer in the temporal domain. Further, 240 Tsuda (2014) stated that the interaction of a sheared wind flow with the topography could 241 be a key parameter for the occurrence of orographic (gravity) waves. In the same year, 242 Teixeira (2014) noted that downstream of the mountains, Lee wave trapping occurs. Owing 243 to wave trapping, the formation of vortices (rotors) can be observed. Recently, Soufflet et 244 al. (2019) showed that for small mountains, trapped Lee waves occur at a small value of 245 the near-surface Richardson number $\left(R i=N^{2} /(\partial U / \partial Z)^{2}\right)$, where $N$ is the Brunt-Väisälä 246 frequency and $U$ is the horizontal wind speed at height $Z$. In our case, the value of $R i=$ 2470.0028 estimated, at $100 \mathrm{~m}$ altitude a.g.l., reveals the presence of trapped Lee waves. The 248 small value of the inverse Froude number $\left(F_{r}^{-1}=0.05\right)$ also supports this condition. 
251 The time-height section of the horizontal wind speed (Fig. 2a) and the RHI radial wind 252 speed (Fig. 2c, d) reveal the presence of low-level jet. The observed wind profiles shown 253 in Figure 4 are in good agreement with Stensrud (1996) and Vera et al. (2006). For a better 254 quantification of the LLJ, we have defined four regions within the boundary layer: the 255 roughness layer, closest to the ground, where there is a constant profile of $U$; the shear 256 layer; the LLJ jet core, and the upper layer. Three crests and troughs, referred to hereafter 257 as Cr1-3 and Tr1-3, have been selected (Fig. 3c) for assessing the impact of LLJ and gravity 258 waves propagation on turbulence.

259 The jet speed $\left(U_{\max }=8 \mathrm{~m} \mathrm{~s}^{-1}\right)$ is similar for these three crests ( $\left.\mathrm{Cr} 1-3\right)$. As expected, the 260 velocities are smaller $\left(\approx 0.75 \times U_{\max }\right)$ for the trough regions (Tr1-3). A small difference of 261 velocities is observed in the LLJ shear layer region for trough and crest regions (Figs. 4 a262 c, blue shading). Moreover, $U$ is nearly similar for Tr1-3 compared to Cr1-3 within the 263 roughness layer. However, the maximum differences of $U$ (for $\operatorname{Tr} 1-3$ compared to $\mathrm{Cr} 1-3$ ) 264 are observed in the upper layer and in the jet core.

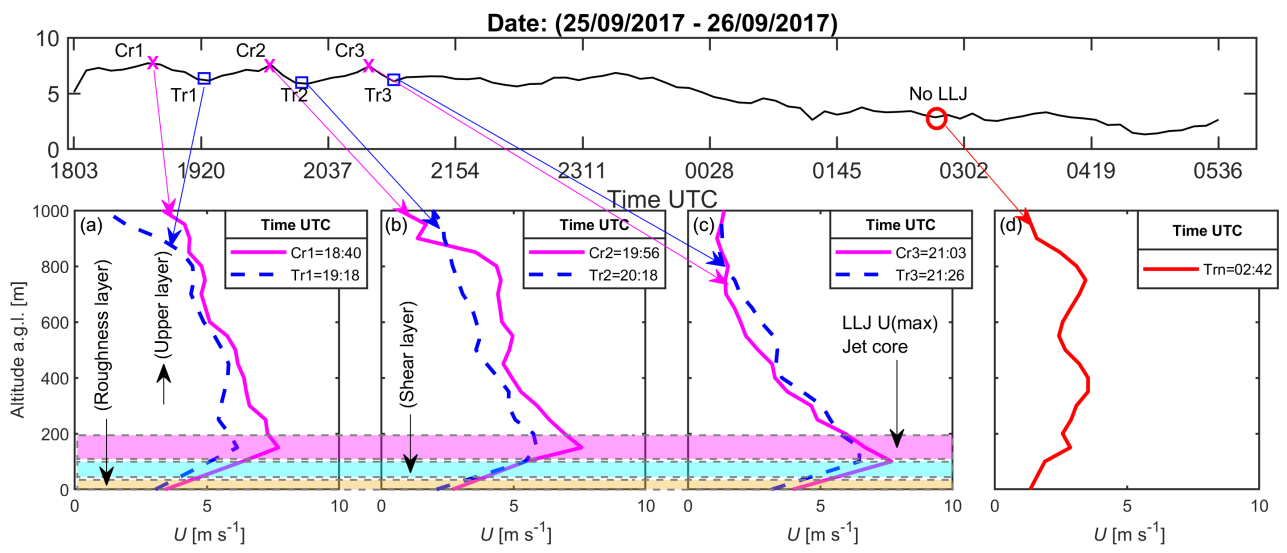

Fig. 4 Vertical profiles of the wind speed $U$ corresponding to three crests and troughs of the propagating gravity wave and low wind conditions; (a) $\mathrm{Cr} 1$ and $\operatorname{Tr} 1$ (b) $\mathrm{Cr} 2$ and $\operatorname{Tr} 2$ (c) $\mathrm{Cr} 3$ and $\operatorname{Tr} 3$, and (d) low wind conditions (no Tr and Cr observed)

In this regard, Storm et al. (2019) stated that the deficiency of vertical mixing might 272 be one of the reasons for the velocity difference in the upper layer compared to the 273 roughness layer. These velocity differences may play an active role in accelerating the wind 
274 speed within the outer layer, unaffected by surface roughness. Furthermore, Figs. 3c and 4

275 reveal that the gravity wave modulates the wind speed periodically.

\subsection{Wind Velocity and Turbulence Assessment near the Ground}

278 Since the primary focus of this study is to evaluate the turbulent properties within the 279 roughness layer, we have analyzed the temporal variations of the velocity vector in the 280 roughness layer using the ultrasonic anemometer data. Figure 5 shows large velocity 281 fluctuations for $u, v, w$ within P-I. These fluctuations are gradually reduced within P-II. 282 This result suggests that larger levels of turbulence are generated during the gravity wave 283 events.

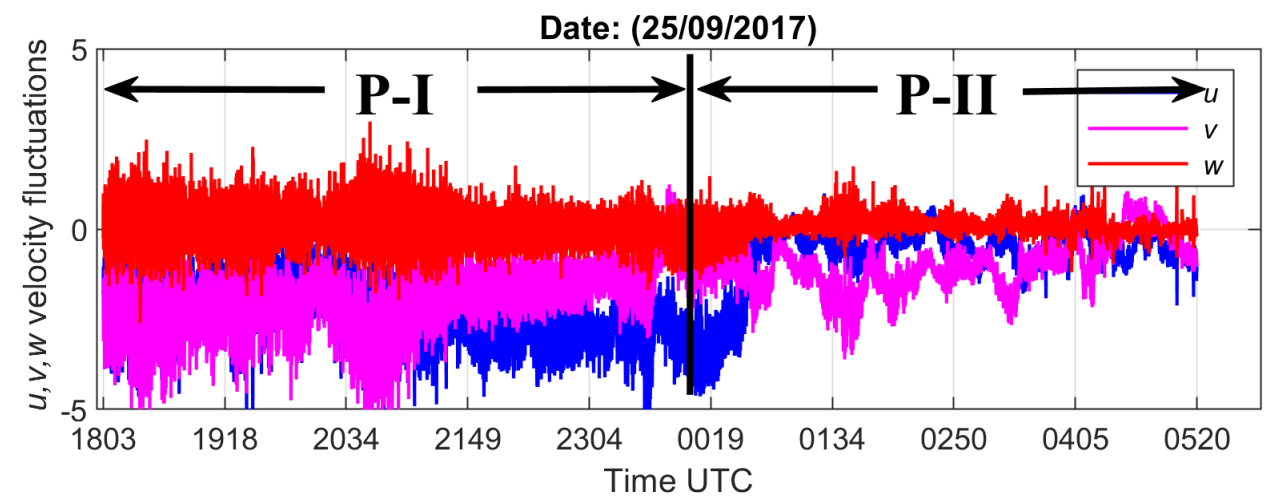

Fig. 5 Time series of $u, v, w$ wind velocity fluctuations $\left(\mathrm{m} \mathrm{s}^{-1}\right)$ in the roughness layer.

Figure $6 \mathrm{~b}-\mathrm{c}$ shows that during the observation period, the dominant wind near the ground was from the north-east. The vertical wind component $(w)$ is slightly positive during P-I $\left(w=0.001 \mathrm{~m} \mathrm{~s}^{-1}\right.$ ) and drops to 0.000 during P-II (Fig. 6a). It is also noticed that the wind speed ranges from 3.5 to $4.5 \mathrm{~m} \mathrm{~s}^{-1}$ at P-I while its variation decreases from 1 to $2 \mathrm{~m} \mathrm{~s}^{-1}$, at P-II (Fig. 6d). The occurrence of larger wind speed at P-I is due to the LLJ.

293 Figure 6e shows the distribution of Reynolds shear stress $R_{u v}, R_{u w}$, and $R_{v w}$ as a 294 function of time. It is evident from Fig. 6e that all three shear stress components are 295 negative at P-I and nearly zero at P-II, which is due to a decrease in wind speed during this 296 period. In a coordinate system aligned with the dominant wind direction, that is from east 297 to west, negative $R_{u v}$ values indicate momentum fluxes from north to south, negative $R_{u w}$ 298 values represent momentum fluxes downward, towards the roughness layer. This signifies 
299 that there is a larger magnitude of momentum at P-I, and that the shear layer is a region of 300 turbulence production. Indeed, we observed a relatively high TKE level during P-I. Figure

3016 also reveals that the variability of the momentum flux $\overline{u^{\prime} w^{\prime}}$ is similar to the maximum wind speed $(U)$ variability shown in Fig. 3c. The gravity wave performs a modulation of

303 the momentum flux, with larger values occurring within crests and lower values within 304 troughs.
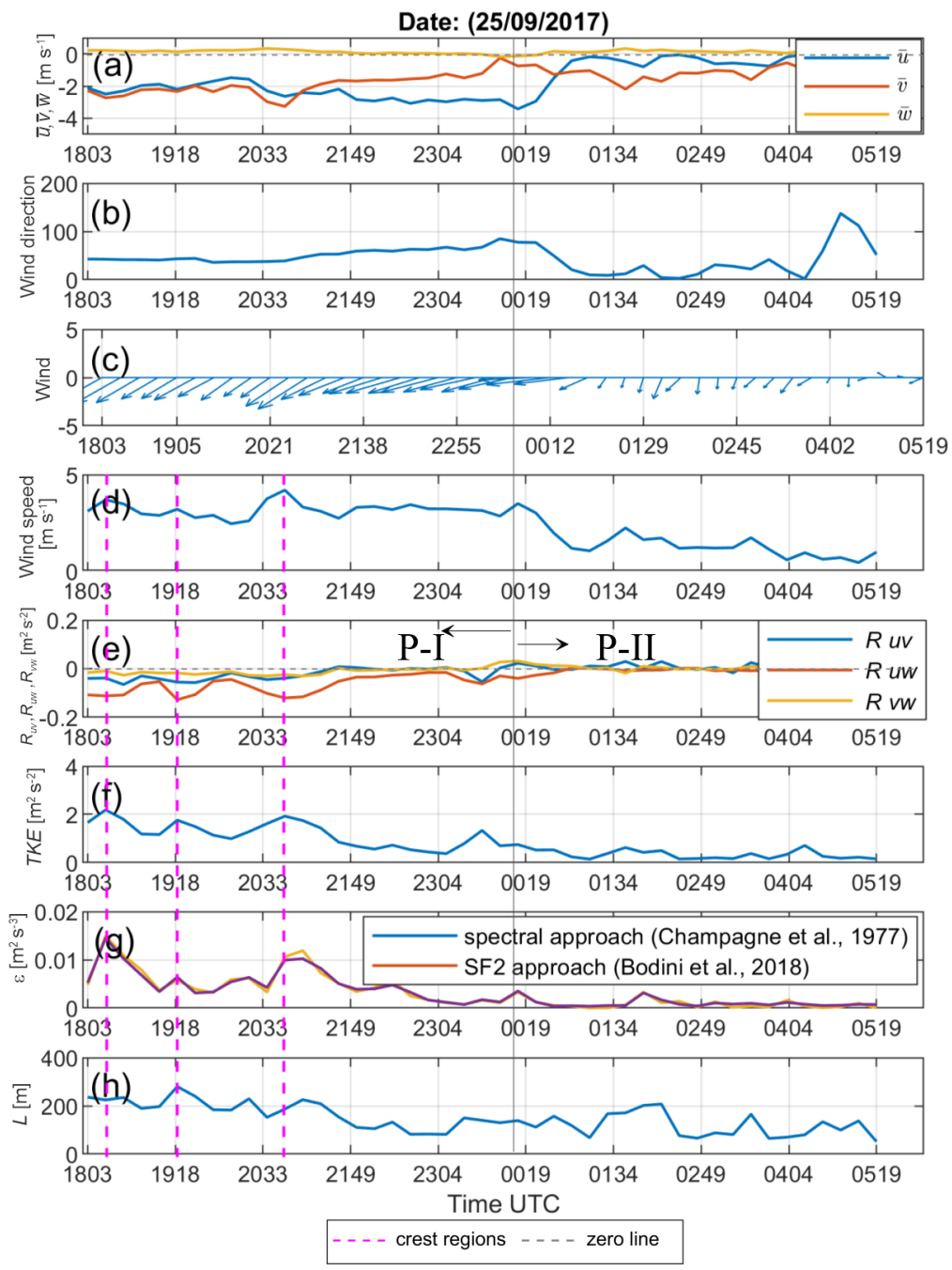

306 Fig. 6 Time series of (a) $u, v, w$ wind velocity components in the roughness layer, 10-min averaged (m s${ }^{-1}$ ); 307 (b) wind direction with respect to the north; (c) wind velocity vector; (d) horizontal wind speed ( $\mathrm{m} \mathrm{s}^{-1}$ ); (e)

308 Reynolds stresses components $R_{u v}, R_{u w}$, and $R_{v w}\left(\mathrm{~m}^{2} \mathrm{~s}^{-2}\right)$; (f) Turbulence kinetic energy $T K E\left(\mathrm{~m}^{2} \mathrm{~s}^{-2}\right)$; $(\mathrm{g})$ energy dissipation rate $\varepsilon\left(\mathrm{m}^{2} \mathrm{~s}^{-3}\right)$; (h) Turbulent length scale $L$ (m) 
311 The temporal variation of TKE (Fig. 6f) shows a similar evolution to that of the wind 312 speed (Fig. 6d), with a variability of $\sim 60$ minutes during P-I. Thus, the maximum energy 313 appears concentrated at crests and minimum at troughs of the propagating gravity wave.

314 Figure $6 \mathrm{~g}$ shows the temporal variation of $\varepsilon$. The wavy distribution of $\varepsilon$ is evident 315 during P-I. This was revealed for $\varepsilon$ estimated by two methods (spectral and SF2 approach). 316 Moreover, the LLJ associated with a gravity wave enhances the turbulent length scale $L$ at 317 P-I (Fig. 6h). Time series of $L$ and $\varepsilon$ (Fig. 6g-h) reveal large periodic variations during P318 I. Near the ground level, the magnitude of variations of the eddy dissipation and turbulent 319 length scale with respect to the mean value attains $50 \%$ and $20 \%$ respectively. These 320 variations are caused by the gravity wave propagating at the height of $100 \mathrm{~m}$ above the 321 ground. The values of $\varepsilon$ deduced from zonal wind component variations by the spectral 322 method and ranging from 0.001 to $0.015 \mathrm{~m}^{2} \mathrm{~s}^{-3}$ are found to be analogous to that estimated 323 by the structure function method.

To ensure the validity of the $\varepsilon$ estimation, the power spectral density (PSD) of $u, v$, and $326 w$ velocity components were calculated and their distribution in frequency domain is shown 327 in Fig. 7, for one particular 10-min interval of measurements by sonic anemometer. The 328 distribution shows that the turbulence is isotropic, and the inertial subrange spans from $f$ $329=0.1$ to $2 \mathrm{~Hz}$ (slope $-5 / 3$ ). In this subrange, there is a Richardson-Kolmogorov energy 330 cascade. The turbulent energy is generated in the frequency range $f=1.5 \times 10^{-2}$ to $\sim 0.1$ $331 \mathrm{~Hz}$. Within the energy-containing range $(<0.1 \mathrm{~Hz})$, the energy production is larger for 332 horizontal components $u$ and $v$ than for the vertical component $w$ within the energy333 containing range $(<0.1 \mathrm{~Hz})$. On the contrary, in the inertial subrange, the energy level of $w$ 334 is found slightly larger (Fig. 7). Similar results are obtained for all intervals of 335 measurements at P-I, and demonstrate the dominance of large-scale horizontal and small336 scale vertical turbulent motions in the flow field during the observation period (P-I). The 337 direct energy transfer through energy cascading occurs in a smaller band of the inertial 338 subrange $(f=0.1 \mathrm{~Hz}-2 \mathrm{~Hz})$ during $\mathrm{P}-\mathrm{I}$, and in a larger band $(f=0.05 \mathrm{~Hz}-2 \mathrm{~Hz})$ during $\mathrm{P}-$ 339 II (results not shown). 


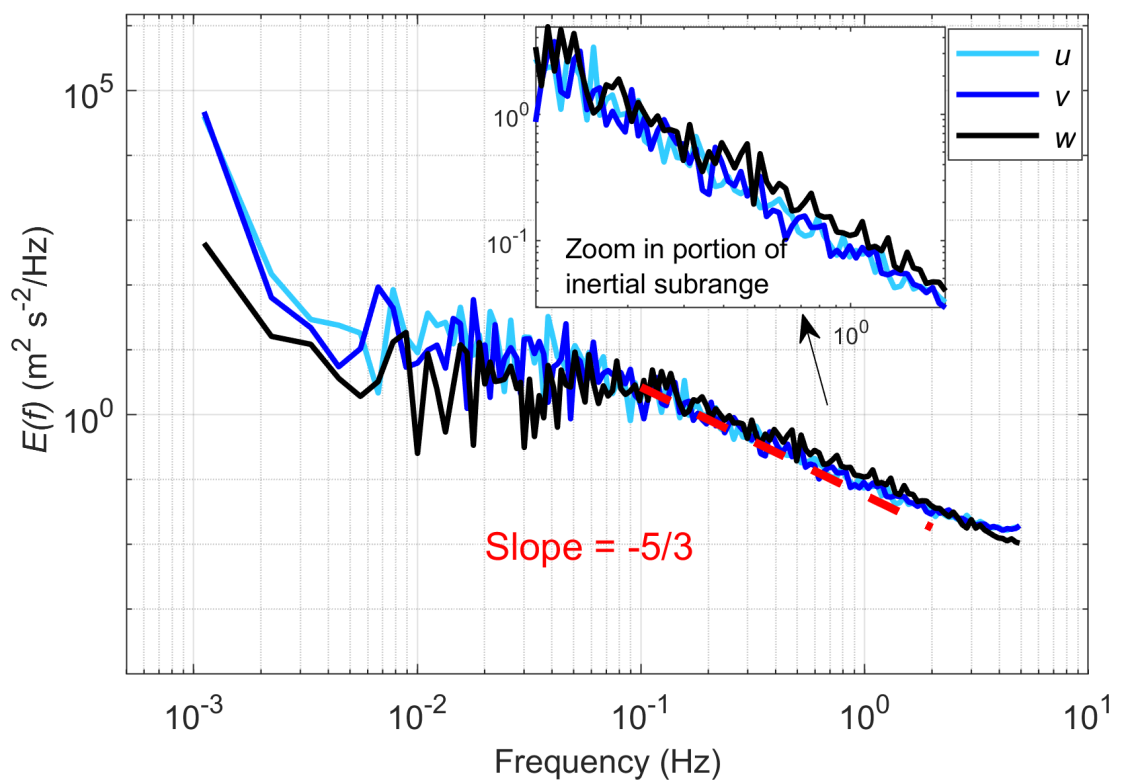

342 Fig. 7 Power spectral density of three $(u, v, w)$ velocity components recorded by sonic anemometer for 10 343 min of measurement (1830-1840).

\section{$345 \quad 3.4$ Assessing Higher-Order Moments and Turbulent Bursting Events}

346 It was shown in Sect. 3.3 that in the roughness layer of the $\mathrm{ABL}$, the shear stress $R_{u w}$

347 experiences a modulation by the gravity wave. Here we analyze $u^{\prime}$ and $w^{\prime}$ time series to 348 better understand the behaviour of their higher-order moments and probability density 349 functions (PDFs). The PDF of $u^{\prime}$ and $w^{\prime}$ have been calculated using a method proposed in 350 Tennekes and Lumley (1972). Figure 8 shows that the maximum of the PDF of $w^{\prime}$ is $\sim 11 \%$ 351 larger than that of $u^{\prime}$, for all the troughs and crests. This means that the probability of 352 occurrence of small fluctuations is larger for the $w$ velocity component than for $u$. 353 Furthermore, observations show that the peak values of $u^{\prime}$ and $w^{\prime}$ distributions at all the 354 troughs are greater than that of at the crests (Fig. 8a). This suggests that the probability of 355 the occurrence of small-scale fluctuations at troughs is larger than at crests. It may be due 356 to the presence of small-scale eddies for lower wind speed in troughs. 


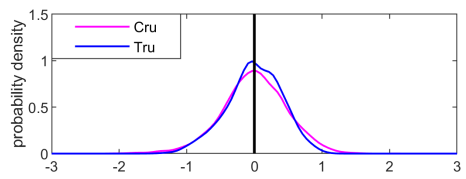

(a)

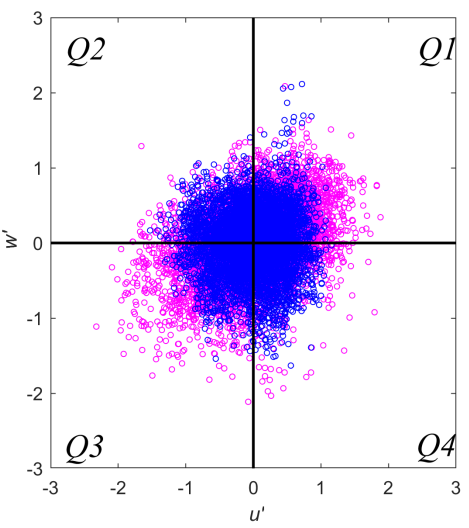

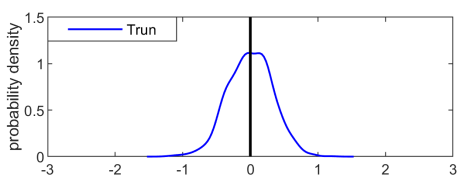

(b)
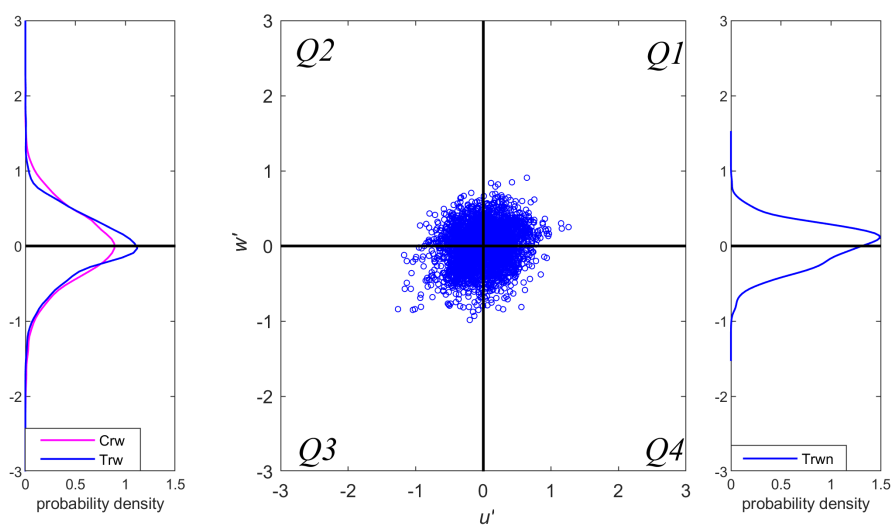

359 Fig. 8 Scatter plots of $u^{\prime}$ and $w^{\prime}$ in four quadrants at the troughs (blue circles) and crests (pink circles) for P-

360 I (a) and P-II (b). The PDF of $u^{\prime}$ and $w^{\prime}$ are presented in the top and right side of scatter plots, respectively.

361 The blue circles in (b) do not represent the velocity perturbations since there is no gravity wave at this time

363 Comparison of panels (a) and (b) in Fig. 8 suggests that the probability of occurrences of 364 small-scale eddies is larger at P-II, without LLJ or gravity wave phenomenon. Wind speed 365 and shear stress are much smaller at P-II than at P-I.

366 The quadrant analysis has been frequently used to characterize the instantaneous wind speed and its direction of propagation (e.g., Lu and Willmarth 1973; Nakagawa and Nezu

368 1977; Raupach 1981; Shaw et al. 1983). In the present study, we have used 10-min long 369 time series at each trough and crest region during P-I and P-II. For each time frame, 370 instantaneous $u^{\prime}$ and $w^{\prime}$ are plotted in the four quadrants. Distributions of the data $\left(u^{\prime}\right.$ and $371 w^{\prime}$ ) in each quadrant represents the behaviour of turbulent bursting events (Nakagawa and 372 Nezu 1977; Raupach 1981). Further, Raupach (1981) stated that the contribution of four 373 events characterizes the total momentum flux $\left(-R_{u w}\right)$. These events are defined in Fig. 9 374 as (Q1) ejection event, (Q2) outward interaction, (Q3) sweep event, and (Q4) inward 375 interaction. These events show the direction of propagation of high and low-speed turbulent 376 eddies. In the present study, the quadrant threshold technique is used to define the 377 influences of turbulent events in the flow field and its contribution to the total shear stress $378 R_{u w}=-\overline{u^{\prime} w^{\prime}}$ in the vertical plane $(u w)$. 
Figure 8a shows the distribution of the largest amount of data in $Q 1$ and $Q 3$ for troughs and crests during P-I. On the contrary, during P-II, an equilibrium in $u^{\prime}$ and $w^{\prime}$ 381 distributions in all four quadrants is observed (Fig. 8b). The velocity fluctuations are more 382 spread in $Q 1$ at crests than the troughs of the gravity wave. The joint distribution of velocity 383 fluctuations shown in Fig. 9 suggests a dominance of low-speed turbulent eddies moving 384 upward (ejection), and high-speed turbulent eddies moving downward (sweep), during the 385 LLJ event. However, turbulence fluctuations are homogeneous for low wind speed $\approx 0.5$ $386 \mathrm{~m} \mathrm{~s}^{-1}$ (Fig. 8b). According to Raupach (1981) and Prabha et al. (2008), the contribution of 387 ejection and sweep is larger than inward and outward interactions for LLJ over a large 388 roughness. Their results are in good agreement with those presented in our study. Hunt and Durbin (1999) stated that the occurrence of intense shear shelters by the large eddies within 390 the lower layer leads to the suppression of turbulence. The present measurements were 391 carried out over a flat surface $10 \mathrm{~m}$ a.g.l. This weak motion is due to the land proximity. 392 The dominance of low-speed upward turbulent eddies is observed in the presence of a LLJ 393 and gravity waves, with larger undulations for crests than troughs.

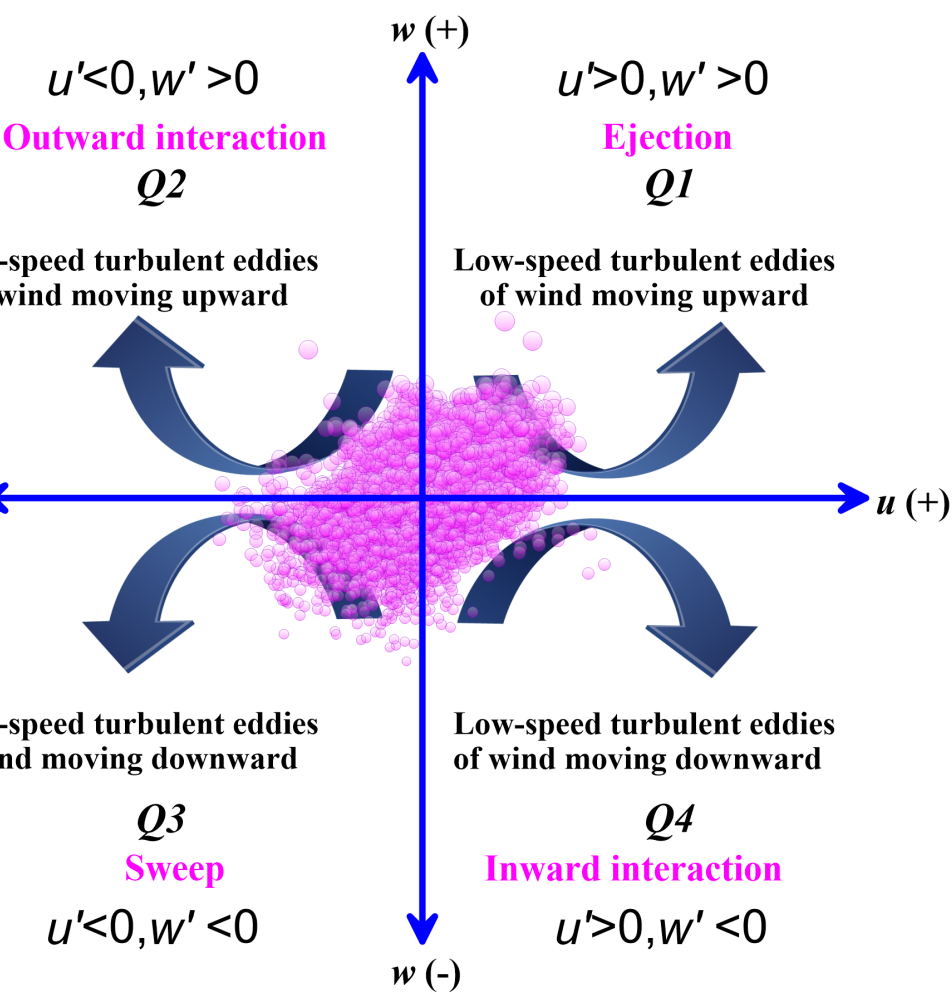

Fig. 9 Definition diagram to portray the characteristics of $u$ and $w$ velocity fluctuations in the four quadrants 


\section{Conclusions}

398 Simultaneous measurements of the wind speed by a sonic anemometer and a lidar

399 performed in a coastal region of France were used for assessing flow variability and 400 turbulence in the atmospheric boundary layer. Observations revealed a dominant wind

401 from the north-east (directed from the land towards the sea) and an occurrence of a LLJ in

402 the boundary layer of the lower troposphere, during the first part of the observation period

403 (P-I), which disappeared during the second part (P-II). The wind speed was approximately

4047 times higher during P-I, with large periodic variations observed within the roughness

405 layer during this period. We found that these periodic variations were caused by an 406 occurrence of orographic (gravity) waves generated by the wind interactions with the local

407 topography, i.e., limited height coastal relief perpendicular to the wind. To the best of our

408 knowledge, the gravity waves collocated with LLJ have been documented for the first time

409 in the coastal region of northeastern France, sought to be a flat plain with only few raised 410 orographic features.

411 Our analysis revealed a modulation of turbulence characteristics in the lower ABL (in 412 the vicinity of the ground) by the gravity waves propagating $\sim 100 \mathrm{~m}$ above the ground.

413 The major effects of the gravity waves on local turbulence are the following:

414 1. The generation of a shear stress of zonal and vertical components appeared larger than 415 that of the meridional component. Larger values of the shear stress and downward 416 momentum flux were found within the crests of the propagating wave.

417 2. The LLJ and the associated gravity wave enhanced the wind turbulence and turbulence 418 kinetic energy dissipation near the ground.

419 3. Near the ground, the size of turbulent eddies varied in a wide range (from $110 \mathrm{~m}$ to 280 $420 \mathrm{~m}$ ) with respect to the wind speed variation controlled by the gravity wave. The size of 421 turbulent eddies was found larger within the wave's crests, while smaller size turbulent 422 eddies were associated with the troughs.

423 4. Large-size eddies were found to generate a downward momentum. This enhanced the 424 downward mass transport from the LLJ shear layer to the roughness layer.

425 5. Assessment of the momentum flux, specifically during the LLJ event, revealed the 426 dominance of low-speed turbulent eddies moving upward (ejection) and high-speed 427 turbulent eddies moving downward (sweep). 
We expect that this study is helpful for understanding the boundary-layer dynamics, turbulence, momentum and energy flux variability in the roughness sublayer in the

430 presence of orographic waves. Additionally, turbulence generated by gravity waves may 431 affect aerosol concentrations through turbulent mixing, and thus contribute to a complex 432 dynamics of the aerosols in the ABL.

434 Acknowledgments The EMPATIE project was funded by the Institut de Recherche Pluridisciplinaire en 435 Sciences de l'Environnement (IRePSE) and the Pôle de Recherche Environnement, Milieux Littoraux et 436 Marins (EMLM) of Université du Littoral Côte d'Opale.

\section{References}

Abdullah AJ (1955) The atmospheric solitary wave. Bull Am Meteorol Soc 36(10):511-518

Augustin P, Billet S, Crumeyrolle S, Deboudt K, Dieudonné E, Flament P, Fourmentin M, Guilbaud S, Hanoune B, Landkocz Y, Méausoone C, Roy S, Schmitt FG, Sentchev A, Sokolov A (2020) Impact of Sea Breeze Dynamics on Atmospheric Pollutants and Their Toxicity in Industrial and Urban Coastal Environments. Remote Sensing 12(4):648

Banta RM, Pichugina YL, Newsom RK (2003) Relationship between low-level jet properties and turbulence kinetic energy in the nocturnal stable boundary layer. J Atmos Sci 60(20):2549-2555

Bialkowski SE (1988) Real-time digital filters: infinite impulse response filters. Analytical Chemistry 60(6):403A-13A

Birgitta K (1998) Low level jets in a marine boundary layer during spring. Contribution to Atmospheric Physics 71:359-373

Bodini N, Lundquist JK, Newsom RK (2018) Estimation of turbulence dissipation rate and its variability from sonic anemometer and wind Doppler lidar during the XPIA field campaign. Atmos Meas Tech

454 Bonner WD (1968) Climatology of the Low Level Jet. Mon. Wea. Rev. 96(12):833-850

455 Bowen BM (1996) Example of Reduced Turbulence during Thunderstorm Outflows. J Appl Meteorol 35(6):1028-1032

Champagne FH, Friehe CA, LaRue JC, Wynagaard JC (1977) Flux measurements, flux estimation techniques, and fine-scale turbulence measurements in the unstable surface layer over land. J Atmos Sci 34(3):515-530

Darby LS, Banta RM, Brewer WA, Neff WD, Marchbanks RD, McCarty BJ, Senff CJ, White AB, Angevine WM, Williams EJ (2002) Vertical Variations in O3 Concentrations before and after a Gust Front Passage. J Geophys Res 107(D13):ACH-9 
463 Droegemeier KK, Wilhelmson RB (1987) Numerical Simulation of Thunderstorm Outflow Dynamics

464 PartI:Outflow SensitivityExperiments andTurbulence Dynamics. J. Atmos.Sci. 44(8):1180-1210

465 Du Y, Chen G (2019) Heavy rainfall associated with double low-level jets over Southern China. Part II:

466 convection initiation. Mon Weather Rev 147(2):543-565

467 Eckermann SD, Vincent RA (1993) VHF radar observations of gravity-wave production by cold fronts over 468 southern Australia. J Atmos Sci 50(6):785-806

469 Fritts DC, Nastrom GD (1992) Sources of mesoscale variability of gravity waves. Part II: Frontal, convective, and jet stream excitation. J Atmos Sci 49(2):111-127

Guest FM, Reeder MJ, Marks CJ, Karoly DJ (2000) Inertia-gravity waves observed in the lower stratosphere over Macquarie Island. J Atmos Sci 57(5):737-752

Hoecker WL (1963) Three Southerly Low-Level Jet Systems Delineated by the Weather Bureau Special Pibal Network of 1961. Mon Weather Rev 91:573-582

Hoffmann L, Xue X, Alexander MJ (2013) A global view of stratospheric gravity wave hotspots located with Atmospheric Infrared Sounder observations. J Geophys Res Atmos 118(2):416-434

Kaimal JC, Finnigan JJ (1994) Atmospheric boundary layer flows: their structure and measurement. Oxford university press

Kallistratova MA, Kouznetsov RD, Kramar VF, Kuznetsov DD (2013) Profiles of wind speed variances within nocturnal low-level jets observed with a sodar. J Atmos Ocean Technol 30(9):1970-1977

Kolmogorov AN (1991) The local structure of turbulence in incompressible viscous fluid for very large Reynolds numbers. Proceedings of the Royal Society of London. Series A: Mathematical and Physical Sciences 434(1890):9-13

Kumer VM, Reuder J, Dorninger M, Zauner R, Grubišić V (2016) Turbulent kinetic energy estimates from profiling wind LiDAR measurements and their potential for wind energy applications. Renew Energy 99:898-910

Lott F, Teitelbaum H (1993) Linear unsteady mountain waves. Tellus a 45(3):201-220

Lu SS, Willmarth WW (1973) Measurements of the structure of the Reynolds stress in a turbulent boundary layer. J Fluid Mech 60(3):481-511

Mitchell MJ, Arritt RW, Labas K (1995) A Climatology of the Warm Season Great Plains Low-Level Jet Using Wind Profiler Observations. Weather Forecast 10(3):576-591

Nakagawa H, Nezu I (1977) Prediction of the contributions to the Reynolds stress from bursting events in open-channel flows. J Fluid Mech 80(1):99-128

Prabha TV, Leclerc MY, Karipot A, Hollinger DY, Mursch-Radlgruber E (2008) Influence of nocturnal low-

497 Plougonven R, Teitelbaum H (2003) Comparison of a large - scale inertia - gravity wave as seen in the 498 ECMWF analyses and from radiosondes. Geophys Res Lett 30(18):1-4 

using high resolution Doppler wind lidar. Journal of Atmospheric and Solar-Terrestrial Physics 123:113123

Raupach MR (1981) Conditional statistics of Reynolds stress in rough-wall and smooth-wall turbulent boundary layers. J Fluid Mech 108:363-382

Raupach M, Finnigan JJ, Brunet Y (1996) Coherent eddies and turbulence in vegetation canopies: the mixinglayer analogy. Boundary-Layer Meteorol 25:351-382

Rinne H (2010) Location-scale distributions_-Linear estimation and probability plotting using MATLAB. Justus-Liebig-Univ., Dept. of Economics and Management Science, Giessen, Germany

Rotach MW, Calanca P (2015) Boundary layer (atmospheric) and air pollution | Microclimate. Encyclopedia of atmospheric sciences 1:258-264

510 Sandu I, van Niekerk A, Shepherd TG, Vosper SB, Zadra A, Bacmeister J, Beljaars A, Brown AR, Dörnbrack A, McFarlane N, Pithan F (2019) Impacts of orography on large-scale atmospheric circulation. npj Climate and Atmospheric Science 2(1):1-8

Shaw RH, Tavangar J, Ward DP (1983) Structure of the Reynolds stress in a canopy layer. Journal of climate and applied meteorology 22(11):1922-31

Schmitt F, Schertzer D, Lovejoy S, Brunet Y (1994) Empirical study of multifractal phase transitions in atmospheric turbulence. Nonlin Process Geophys 1: 95-104

Smedman AS, Högström U, Hunt JC (2004) Effects of shear sheltering in a stable atmospheric boundary layer with strong shear. Q J R Meteorol Soc 130(596):31-50

Soufflet C, Lott F, Damiens F (2019) Trapped mountain waves with a critical level just below the surface. Q J R Meteorol Soc 145:1503-1514

Stensrud DJ (1996) Importance of low-level jets to climate: A review. J Clim 9(8):1698-711

Storm B, Dudhia J, Basu S, Swift A, Giammanco I (2009) Evaluation of the weather research and forecasting model on forecasting low - level jets: Implications for wind energy. Wind Energy: An International Journal for Progress and Applications in Wind Power Conversion Technology 12(1):81-90

Taylor GI. Statistical theory of turbulence. IV (1935) Diffusion in a turbulent air stream. Proceedings of the Royal Society of London. Series A-Mathematical and Physical Sciences 151(873):465-78 atmosphere) radar and GPS (Global Positioning System) radio occultation. Proceedings of the Japan

533 Uccellini LW, Koch SE (1987) The synoptic setting and possible energy sources for mesoscale wave 534 disturbances. Mon Weather Rev 115(3):721-9 
535 Vaughan G, Hooper D (2015) Mesosphere-Stratosphere-Troposphere and Stratosphere-Troposphere Radars 536 and Wind Profilers. Encyclopedia of Atmospheric Sciences Second Edition (1): 29-437

537 Vera C, Baez J, Douglas M, Emmanuel CB, Marengo J, Meitin J, Nicolini M, Nogues-Paegle J, Paegle J, 538 Penalba O, Salio P (2006) The South American low-level jet experiment. Bull Am Meteorol Soc $539 \quad 87(1): 63-78$

540 Wei W, Zhang HS, Schmitt FG, Huang YX, Cai XH, Song Y, Huang X, Zhang H (2017) Investigation of

541 Turbulence behaviour in the stable boundary layer using arbitrary-order Hilbert spectra. Boundary-Layer 542 Meteorol. 163(2):311-26

543 Whiteman CD, Bian X, Zhong S (1997) Low-Level Jet Climatology from Enhanced Rawinsonde 544 Observations at a Site in the Southern Great Plains. J Appl Meteorol 36(10):1363-1376

545 Zhong S, Fast JD, Bian X (1996) A Case Study of the Great Plains Low-Level Jet Using Wind Profiler

546 Network Data and a High-Resolution Mesoscale Model. Mon Weather Rev 124(5):785-806

547

548

549 